\title{
Anti-Obesity Pharmacotherapy: The Intercontinental Regulatory Divide
}

\author{
Andrew J. Krentz ${ }^{1} \cdot$ Ken Fujioka ${ }^{2}$ Marcus Hompesch ${ }^{1}$
}

Published online: 12 May 2015

(C) Springer International Publishing Switzerland 2015

Obesity, while recognized as a pressing global public health issue, does not present an immediate threat to life. Accordingly, weight-reducing medication is required to be exceptionally safe [1]. Since the 1960s, several agents have been withdrawn in the USA or Europe because of toxicity issues (Table 1) [2]. Two events in particular helped change the regulatory and marketing landscape concerning the development, registration, and commercialization of weight-reducing drugs. The first was the suspension in 2008 by the European Medicines Agency (EMA) of marketing authorization for the cannabinoid receptor type 1 inverse agonist rimonabant following reports of psychiatric adverse events including suicidal ideation [3]. The second was the demise of sibutramine, a serotonin-norepinephrine reuptake inhibitor, in 2010 in response to the results of a post-marketing safety trial that demonstrated an increased risk of non-fatal myocardial infarction and stroke in patients with pre-existing cardiovascular disease [4].

The regulatory environment in the USA and Europe for new anti-obesity drugs has become increasingly challenging in recent years [5]. Key points of current US FDA guidance include the need to demonstrate weight control over 1 year [6]. Required placebo-subtracted weight loss is $\geq 5 \%$ and/or the percentage of subjects losing $\geq 5 \%$ of baseline bodyweight has to be $\geq 35 \%$ and double the

Andrew J. Krentz

andrew.krentz@profilinstitute.com

1 Profil Institute for Clinical Research, 855 3rd Avenue, Suite 4400, Chula Vista, CA, USA

2 Department of Diabetes and Endocrinology, Center for Weight Management, Scripps Clinic Del Mar, San Diego, CA, USA

percentage observed with placebo [7]. To satisfy safety requirements, a minimum of 3000 subjects would have to be assigned to the experimental drug, with no fewer than 1500 subjects assigned to placebo for a 1 -year period $[6,8]$. The EMA requires a $10 \%$ reduction from baseline body weight at 1 year that must also be at least $5 \%$ greater than that achieved with placebo [9]. If weight loss at the end of 1 year is $10 \%$ or more, the proportions of responders in different treatment arms can be considered as an alternative primary efficacy criterion.

The aforementioned safety issues have helped created a risk-averse regulatory environment that has become more pronounced in Europe than in the USA [2]. The resulting transatlantic divide in availability of weight-reducing drugs, which has only very recently started to narrow, has generated concern among European obesity experts [10].

Four drugs have recently been approved by the FDA: lorcaserin (2012), phentermine/topiramate extended release (ER) (2012), naltrexone hydrochloride/bupropion hydrochloride ER (2014), and liraglutide $3.0 \mathrm{mg}$ (2014). Of these, only naltrexone hydrochloride/bupropion hydrochloride ER and liraglutide have received a positive recommendation by the EMA's Committee for Medicinal Products for human use (CHMP). Some of the recent approvals represent something of a volte face by the FDA. Phentermine/topiramate was originally rejected because of safety concerns, with approval finally coming with a Risk Evaluation and Mitigation Strategy (REMS). The latter highlighted the possible increased risk of congenital malformation, specifically orofacial clefts, in infants exposed to the drug during the first trimester of pregnancy. Furthermore, the FDA required the manufacturer to perform ten post-marketing studies, including a long-term cardiovascular outcomes trial. The selective $5-\mathrm{HT}_{2 \mathrm{c}}$ receptor agonist lorcaserin was also initially rejected by the FDA due to concerns about tumour growth in rodents. As a 
Table 1 Anti-obesity drug approvals and withdrawals

\begin{tabular}{|c|c|c|c|}
\hline & Year approved & Year withdrawn & Reason for withdrawal \\
\hline \multicolumn{4}{|l|}{ FDA } \\
\hline Desoxyephedrine & 1947 & & \\
\hline Phenmetrazine & 1956 & & \\
\hline Phentermine $^{\mathrm{a}}$ & 1959 & & \\
\hline Diethylpropion & 1959 & & \\
\hline Phendimetrazine & 1959 & & \\
\hline Benzphetamine & 1960 & & \\
\hline Mazindol & 1973 & & \\
\hline Fenfluramine & 1973 & 1997 & Cardiac valvulopathy; pulmonary hypertension \\
\hline Phenylpropanolamine ${ }^{\mathrm{b}}$ & & 2000 & \\
\hline Dexfenfluramine & 1996 & 1997 & \\
\hline Sibutramine & 1997 & 2010 & Excess of non-fatal cardiovascular events in SCOUT \\
\hline Orlistat & $1999^{c}$ & & \\
\hline Lorcaserin & 2012 & & \\
\hline Phentermine + topiramate-ER & 2012 & & \\
\hline Naltrexone + bupropropion & 2014 & & \\
\hline Liraglutide $3.0 \mathrm{mg}$ & 2014 & & \\
\hline \multicolumn{4}{|l|}{ EMA } \\
\hline Benfluorex & 1976 & 2009 & Cardiac valvopathy; pulmonary hypertension \\
\hline Rimonabant & 2006 & 2009 & Severe mood disorders including suicidal ideation \\
\hline Naltrexone + bupropropion & 2014 & & \\
\hline Liraglutide $3.0 \mathrm{mg}$ & 2014 & & \\
\hline
\end{tabular}

EMA European Medicines Agency, ER extended release, FDA US Food and Drug Authority

a Often used in combination with fenfluramine ('phen/fen') until withdrawal of the latter in 1997

b Phenylpropanolamine was in use prior to 1962 when an amendment to the US food and drug laws required a retrospective review of its effectiveness. Final approval was deferred because of safety concerns about a possible association between phenylpropanolamine use and stroke. Phenylpropanolamine was an ingredient of many over-the-counter medications in the USA prior to its withdrawal. The drug remains available in some European countries

c Also available over the counter in reduced doses

stipulation of the approval of lorcaserin, six post-marketing studies, including a long-term cardiovascular outcomes trial, were required. To reduce exposure to ineffective therapy, both drugs are required to be discontinued (or in the case of phentermine/topiramate ER, the dose must be discontinued or increased) after 12 weeks if dose-specific weight loss targets have not been achieved. In 2011, the FDA initially declined approval of naltrexone hydrochloride and bupropion hydrochloride ER pending the results of an additional cardiovascular safety trial; eventual approval in 2014 came with the stipulation of an additional cardiovascular outcomes trial focused on cardiovascular safety. FDA approval for liraglutide $3.0 \mathrm{mg}$ was also subject to a REMS consisting of a communication plan to inform healthcare professionals about risks associated with the drug and a requirement for post-marketing trials.

As with all novel drugs, it is difficult to predict all potential adverse events as a medication moves from preclinical to clinical development. Validated animal models and preclinical and/or toxicological screens to accurately predict the toxicity of anti-obesity drugs are lacking (Table 1) [11]. In any case, adverse effects that occur at low rates are unlikely to be identified without recourse to large post-marketing trials or extensive and effective post-marketing monitoring. Improving the quality of phase III trials with study designs that specifically address potential problems, e.g., multiple echocardiograms in the case of lorcaserin, can help de-risk new anti-obesity drugs. Calls have been made for regulatory agencies and the pharmaceutical industry to work together towards an improved paradigm to facilitate the development and application of the next generation of obesity pharmacotherapy. For now, the divergent conclusions of the FDA and the EMA sit uneasily alongside one another while US obesity specialists continue to enjoy an advantage over their European counterparts in the drugs at their disposal. 
Funding and conflicts of interest Profil Institute for Clinical Research (AJK, MH) undertakes early-phase clinical research of new drugs for obesity and diabetes. KF reports receipt of grant funding and/or speakers' fees for companies including Abbott, Novo Nordisk, Orexigen, and Vivus. The views expressed are those of the authors. No funding was received for the preparation of this article.

\section{References}

1. Cheung B, Cheung TT, Samranayake NS. Safety of antiobesity drugs. Ther Adv Drug Safety. 2013;4:171-81.

2. Krentz AJ FK, Hompesch M. Evolution of pharmacological obesity treatments: Focus on the history of adverse side-effect profiles. Pharmaco Economics (in press).

3. Ioannides-Demos LL, Piccenna L, McNeil JJ. Pharmacotherapies for obesity: past, current, and future therapies. J Obes. 2011;2011:179674.

4. James WP, Caterson ID, Coutinho W, et al. Effect of sibutramine on cardiovascular outcomes in overweight and obese subjects. N Engl J Med. 2010;363:905-17.
5. Rodgers RJ, Tschop MH, Wilding JP. Anti-obesity drugs: past, present and future. Dis Models Mech. 2012;5:621-6.

6. Food and Drug Administration. Guidance for industry developing products for weight management. 2007. http://www.fda.gov/ downloads/Drugs/Guidances/ucm071612.pdf. Accessed 5 Mar 2015.

7. Colman E. Food and Drug Administration's Obesity Drug Guidance Document: a short history. Circulation. 2012;125:2156-64.

8. Sonnenberg G, Matfin G, Reinhardt RR. Drug treatments for obesity: where are we heading and how do we get there? Br J Diabetes Vasc Dis. 2007;7:111-8.

9. Manning S, Pucci A, Finer N. Pharmacotherapy for obesity: novel agents and paradigms. Ther Adv Chronic Dis. 2014;5:135-48.

10. Astrup A, Rossner S, Finer N, Van Gaal L. Obesity in Europedoes anybody care? Expert Opin Pharmacother. 2013;14:971-3.

11. Elangbam CS. Review paper: current strategies in the development of anti-obesity drugs and their safety concerns. Vet Pathol. 2009;46:10-24. 